\title{
Primary Anorectal Malignant Melanoma: A Single Center Experience
}

\section{Primer Anorektal Malign Melanom: Tek Merkez Deneyimi}

\author{
$\underline{\text { Havva Yeșil Çınkır }}{ }^{1}$, Fatih Yıldız², Ferit Aslan², Ilkay Dogan ${ }^{3}$, Ulku Yalcintas Arslan², Özlem Sönmez ${ }^{2}$, Umut \\ Demirci $^{2}$, Berna Öksüzoğlu ${ }^{2}$ \\ ${ }^{1}$ Gaziantep Üniversitesi Tıp Fakültesi, Tıbbi Onkoloji, Gaziantep, Türkiye \\ ${ }^{2}$ Dr. Abdurrahman Yurtaslan Ankara Onkoloji Eğitim ve Araştırma Hastanesi, Tıbbi Onkoloji, Ankara, Türkiye \\ ${ }^{3}$ Gaziantep Üniversitesi Tip Fakültesi, Biyoistatistik, Gaziantep, Türkiye
}

Dergiye Ulaşma Tarihi: 21.05.2019 Dergiye Kabul Tarihi:13.09.2019 Doi: 10.5505/aot.2020.81594

\section{ÖZET}

GÍRIŞ ve AMAÇ: Primer anorektal malign melanom (ARMM) nadir tümördür. Anorektal karsinomların \%1'ini melanomlar oluşturur. Prognozu kötüdür, 5 yıllık sağkalım oranı \%10’dur. Biz çalışmamızda nadir görülen tümör olması nedeni ile ARMM tanılı hastaları değerlendirdik.

YÖNTEM ve GEREÇLER: ARMM tanısı ile Ekim 1998- Şubat 2019 tarihleri arasında takip edilen 21 hastanın dosya bilgileri retrospektif olarak incelendi. Hastaların demografik, klinik, radyolojik ve sağkalım özellikleri kayıt edildi. Sağ kalım analizleri için Kaplan-Meier sağ kalım analizi kullanıldı.

BULGULAR: Hastaların yaş ortalaması 59,5 $\pm 13,3$ (28-76); 8 (\% 38,1)' i erkek, 13 (\% 61,9)'ü kadın cinsiyetteydi. Tümör lokalizasyonuna göre 8 (\% 38,1)'i anal bölge, 11 (\% 52,4)'i rektal bölge ve $2(\%$ 9,5)’ si anorektal bölge yerleşimliydi. Sağkalım analizine göre genel sağkalım (GSK) 16 ay ( \%95 Güvenlik Aralığı (GA); 13,2-18,7) idi. Tanıda metastaz olup olmamasına göre ortanca GSK erken evrede 18 ay (\% 95 GA;15,620,3), metastatik hastalıkta 11 ay (\%95 GA;4,5-17,4) olarak saptandı (p: 0,003).

TARTIŞMA ve SONUÇ: ARMM şu an için herhangi bir tedavi kılavuzuna sahip değildir, terapötik yöntemin seçimi dikkatle düşünülmelidir. Erken teşhis ve özelleştirilmiş, multidisipliner bir tedavi planı muhtemelen ARMM'nin tedavi sonucunu iyileştirir.

Anahtar Kelimeler: anorektal hastalıklar, malign melanom, sağkalım

\begin{abstract}
INTRODUCTION: Primary anorectal malignant melanoma (ARMM) is a rare tumor. Melanomas form $1 \%$ of anorectal carcinomas. The prognosis is poor, the 5-year survival rate is $10 \%$. In our study, we evaluated patients with ARMM because of the rare tumor.

METHODS: The patient information of 21 patients with ARMM between October 1998 and February 2019 were retrospectively reviewed. Demographic, clinical, radiological and survival characteristics of the patients were recorded. Kaplan-Meier survival analysis was used for survival analysis.

RESULTS: The mean age of the patients was $59,5 \pm 13,3$ years $(28-76) ; 8(38,1 \%)$ were male and $13(61,9 \%)$ were female gender. According to tumor localization, $8(38,1 \%)$ anal region, $11(52,4 \%)$ rectal region and 2 $(9,5 \%)$ were located in the anorectal region. Overall survival (OS) was 16 months (95\% Confidence Interval (CI); 13,2-18,7) according to survival analysis. According to the diagnosis of metastasis, the median OS in the early stage was 18 months (95\% CI;15,6-20,3); 11 months (95\% CI;4,5 $\pm 17,4)$ in metastatic disease (p: 0,003).

DISCUSSION AND CONCLUSION: The ARMM does not currently have any treatment guidelines, the choice of the therapeutic method should be carefully considered. Early diagnosis and a personalized, multidisciplinary treatment plan will probably improve the outcome of ARMM treatment.

Keywords: anorectal diseases, malignant melanoma, survival
\end{abstract}

\section{GíRiş}

Primer anorektal malign melanom (ARMM) nadir tümördür. Anorektal karsinomların \%1'ini melanomlar oluşturur (1). Tüm melanomların \%0,4-1,6's1 anorektal bölgeden kaynaklanmaktadır, cilt ve retina melanomu sonrası 3. sıradadır (2). Baş-boyun ve kadın genital sistemi sonrası üçüncü en yaygın mukozal malign melanom bölgesidir (3). Prognozu kötüdür, 5 yıllık sağkalım oranı \%10'dur (1). Başlangıç semptomlarını sıklıkla 
rektal kanama, barsak alışkanlıklarında değişiklik ve asemptomatik lokal kitle oluşturmaktadır, bu nedenle hemoroid, polip ve rektal kanser ile karışmaktadır (2). Dentat çizginin yakınında sıklıkla oluşur. Tümörün oldukça invaziv olması ve dentat çizginin yakınında lenfatik damarların çok sayıda bulunmasından dolayı hastalığın erken döneminde lokal yayılım ve uzak metastazlar sıklikla saptanmaktadır (4). Histopatolojik yanlış tanı konulması nadir değildir, özellikle amelanositik olgularda lenfoma, karsinoma ve ya sarkom ile karışabilmektedir (5). Çalışmamızda, nadir görülen tümör olması nedeni ile anorektal malign melanom tanilı hastaları değerlendirmeyi amaçladık.

\section{GEREÇ VE YÖNTEM}

Çalışmamız Uluslararası Helsinki Bildirgesi’ne uygun olarak planlandı ve lokal etik kurul onayı alındı (Gaziantep Üniversitesi Klinik Araştırmalar Etik Kurulu, Karar no:2019/109, 13.03.2019). ARMM tanis1 ile Ekim 1998Şubat 2019 tarihleri arasında S.B.Ü. Dr. Abdurrahman Yurtaslan Ankara Onkoloji Eğitim ve Araştırma Hastanesi'nde takip edilen 21 hastanın dosya bilgileri retrospektif olarak incelendi. Hastaların demografik ve klinik özellikleri, cerrahi ve onkolojik tedavi öyküleri, ulusal ölüm bildirim sisteminden ölen hastaların ölüm tarihleri, yaşayan hastaların son kontrol zamanından takip süreleri kayıt edildi.

Tanımlayıcı istatistiklerde, sürekli değişkenler ortalama \pm standart sapma, kategorik değişkenler yüzde biçiminde ifade edildi. Nüksler, hastaların kayıt bilgilerine ve radyolojik görüntüleme sonuçlarına göre belirlendi. Genel sağkalım (GSK) süresi, patoloji tanı tarihinden itibaren ölüm veya son takip süresi arasındaki zaman olarak hesaplandı. Sağ kalım analizleri için KaplanMeier sağ kalım analizi kullanıldı. İstatistiksel değerlendirmeler SPSS 22.0 program kullanılarak hesaplandı.

\section{BULGULAR}

Hastaların ortanca yaşı 59 (28-76); 8 (\% 38,1)' i erkek, 13 (\% 61,9)'ü kadın cinsiyetteydi. Başvuru şikayetlerine göre; anal bölgeden kanama $10(\% 47,6)$, anal bölgede ağrı 7 (\% 33,3), anal bölgede kitle 4 (\% 19) hastada mevcuttu. Tümör lokalizasyonuna göre 8 (\% 38,1)'i anal bölge, 11 (\% 52,4)'i rektal bölge ve $2(\% 9,5)$ ' si anorektal bölge yerleşimliydi. Tanı anında 3 hasta ikinci evre, 12 hasta üçüncü evre ve 6 hasta dördüncü evre idi. Uygulanan operasyon şekline göre $15(\% 73,7)$ hastaya küratif, $5(\% 26,3)$ hastaya palyatif işlem yapıldı, 1 hastaya cerrahi işlem uygulanmadı. Hastaların $6(\% 28,6)$ ' sinda tanı anında metastaz mevcuttu. $6(\% 28,5)$ hastaya adjuvan interferon tedavisi verildi. Tablo 1'de hastaların demografik ve klinik özellikleri gösterilmektedir. Metastatik evrede olan 5 (\% $23,8)$ hasta 1 basamak, $4(\% 21,1)$ hasta 2 basamak, $3(\%$ 15,8) hasta 4 basamak tedavi ald. İmmunoterapi olarak ise 1 hasta ipilumumab tedavisi aldı. Analiz sirasinda 18 (\% 85,7) hastada ölüm olayı gözlendi, 3 (\% $14,2)$ hasta yaşıyordu. Sağkalım analizine göre GSK süresi 16 ay (\% 95 Güvenlik Aralığ1 (GA);13,2-18,7) idi (Şekil 1). Tanıda metastaz olup olmamasina göre ortanca GSK erken evrede 18 ay (\% 95 GA;15,6-20,3) iken metastatik hastalıkta 11 ay (\% 95 GA;4,5-17,4) olarak saptandı (p:0,003) (Şekil 2).

\section{TARTIŞMA}

Anorektal malign melanoma kötü prognoz ile seyreden, nadir tümördür. Küratif cerrahi ve kemoterapiye rağmen 5 yıllık sağkalım oranı \% 4-31'dir (6). İlk kez 1857 y1lında Moore DW tarafinca tanımlandı (7). Sönmez ve ark. 1998-2010 yılları arasında merkezimizde takip edilen hastalar ile yayınlanan makalesinde hasta sayısı dokuz idi (8). Merkezimiz, kanser hastalarının ağırlıklı olarak takip ve tedavi edildiği bir ünite olmasına rağmen, tümörün 
nadir olarak görülmesi nedeni ile 21 yıllık süreçteki ARMM tanılı hasta sayısı azdır.

Hastalığın etiyolojisi bilinmemektedir (9). Ortalama tanı yaşı 60 yaş ve üzeridir ve kadınlarda sıklıkla görülür (10). Çalışmamızdaki bulgular da literatür ile uyumlu olarak saptand. ARMM'ler çoğunlukla anal kanal veya anal verge bölgesinde yer almakta iken (3) hastalarımızın çoğunluğunda tümör yerleşimi rektal bölgede idi. Yayınlanmış olan çalışmalarda metastatik evre oranları \%22-38 olarak bildirilmiştir $(10,11)$. Çalışmamızda literatür ile uyumlu olarak benzer oranlar saptandi.

ARMM'un tedavi yönetimi zordur. Düşük insidansı nedeniyle yayınların çoğu vaka raporları veya serileri şeklindedir. ARMM için cerrahi rezeksiyon, kemoterapi ve radyoterapi dahil olmak üzere çeşitli tedavi yöntemleri önerilmiş olsa da, hepsi tartışmalıdır ve kanıt yeterli değildir. Ayrıca, nadir olması nedeniyle ARMM'de randomize kontrollü bir çalışma mümkün değildir. Diğer malign hastalıklarda olduğu gibi tümörün boyutu, hastanın yaşı, komorbid hastalıkları ve metastaz durumuna göre tedavi planı yapılmalıdır. Cerrahi rezeksiyon temel tedaviyi oluşturmakta olup abdominoperineal rezeksiyon (APR) ve geniş lokal eksizyon cerrahi seçenekleri olarak önerilmektedir (12). APR, geniş cerrahi sınır güvenliği sağlaması ve mezenterik lenf nodlarına yayılımı azaltması nedeni ile nüks riskini kontrol etmektedir. APR ile geniş cerrahi rezeksiyon arasında yaşam süresi açısından farklılık gösterilememiştir. APR ile morbidite oranları yüksek ve kolostomi ilişkili yaşam kalitesinde düşme gözlenmektedir. $\mathrm{Bu}$ nedenlerden dolay1 geniş lokal eksizyon ile cerrahi sınırın negatif sağlandığ1 durumlarda APR geri planda önerilmektedir. Hastalarımızın çoğunluğuna küratif olmak üzere tüm hastalarımıza cerrahi işlem olarak APR uygulanmıştı. Bunun nedeni olarak hastalarda başvuru sırasında kanama benzeri acil müdahale gerektiren semptomların mevcut olması idi.
Cerrahi eksizyon sonrası dönemde adjuvan radyoterapi uygulanabilmektedir (13). $\mathrm{Bu}$ tedavi seçeneği ile lokal bölgesel nüks oranları azalmaktadır, fakat bu hastalarda esas ölüm nedeni uzak metastazdır. Çalışmamızda hastalara cerrahi sonrası adjuvan RT uygulanmamıştı. Bunun nedeni olarak tüm hastalara APR operasyonu yapılmış olması ve lokal kontrolün bu yöntemle sağlanmış olması düşüncesi idi.

Standart kemoterapi rejimi mevcut değildir. Buna ek olarak, AMM nadirliği sistemik tedavinin klinik etkinliğini değerlendirmeyi zorlaştırmaktadır. Dacarbazine, Bacile Calmette-Gurin (BCG), levamizol, cisplatin, vinblastin, interlökin-2 ve interferon gibi birçok tedavi rejimi araştırılmıştır (10). Mukozal melanomlarda, özellikle lenf nodu tutulumu olan hastalarda, adjuvan tedavide alfa-interferon tedavisinin relapssız sağkalım ve GSK'da uzama sağladığ 1 gösterilmiştir (14). Geleneksel sitotoksik tedavilerin etkinliği düşük, yan etki görülme olasılı̆̆1 yüksektir. Son zamanlarda kütanöz metastatik melanomada immünoterapi ve hedefe yönelik tedavi alanında önemli ilerlemeler kaydedilmiştir. Ipilimumab, sitotoksik T-lenfosit antijen 4'ü (CTLA-4) hedef alan insan monoklonal antikorudur. Metastatik melanoma hastalarında genel sağkalımı iyileştiren ilk ajandır (15). Ayrıca BRAF-V600E mutasyonu olan hastalarda hastalıksız ve GSK yararı olduğu gösterilen vemurafenib de metastatik melanomda kullanılmaktadır. KIT mutasyonu mevcut olan hastalarda bu yolağı hedefleyen inhibitör ajanların (imatinib, sunitinib, dasatinib) etkinliği gösterilmiştir (16). Hastalarımıza ilaç erişiminin kolay olması, tanı ve tedavi sürecinde güncel hedef tedavilerin yaygin olmaması nedeni ile geleneksel kemoterapiler (dakarbazin, sisplatin, temozolamide) uygulanmıştı. Hastalarımızın çoğunluğunun geçmiş dönemde tanısı konulmuş hastalar olması nedeni ile tüm hastalara B-RAF, c-kit testleri yapılamadi. 
Literatürde bildirilen sağkalım sonuçları Anvari ve ark. çalışmasında 4 ay, Belkara ve ark. çalışmasında ise 8 ay olarak saptanmıştır $(17,18)$. Çalışmamızda sağkalım sonuçları literatüre göre daha iyi saptandi. Bu durumda hastaların daha erken doktora başvuru yapmaları ve hastalığın bilinirliğinin artmış olmasının katkısı olabilir.

\section{SONUÇ}

ARMM şu an için herhangi bir tedavi kılavuzuna sahip değildir, tedavi yönetiminin

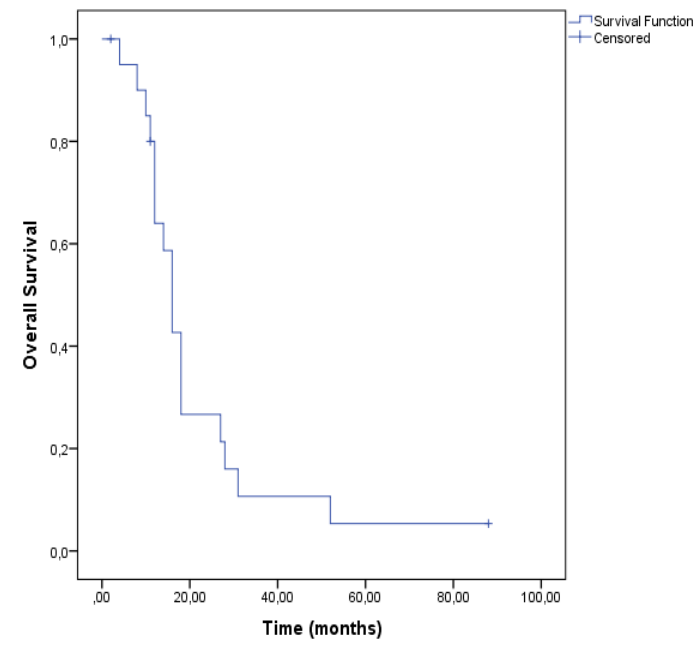

Şekil 1: Tüm hastalarda genel sağ kalım grafiği (Ortanca GSK 16 ay (\%95 GA;13,2-18,7) seçimi dikkatlice yapılmalıdır. Erken teşhis ve özelleştirilmiş, multidisipliner bir tedavi planı muhtemelen ARMM'nin tedavi sonucunu iyileştireceği öngörülmektedir. ARMM'un etkili tedavilerini araştırmak için gelecekte büyük çaplı prospektif klinik çalışmalar yapılmalıdır.

\section{Çıkar çatıșması: Yok}

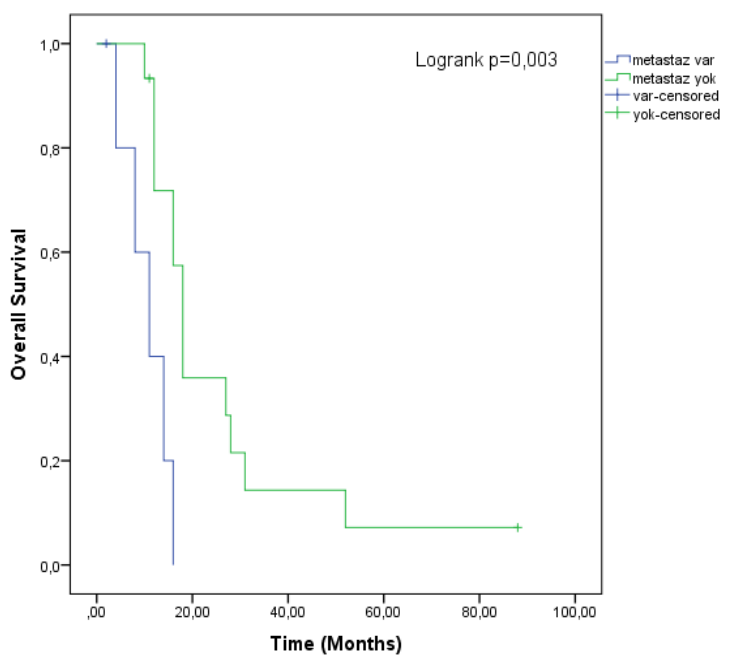

Şekil 2: Tanıda metastaz olup olmamasına göre sağkalım analizi (Erken evre kanserde ortanca GSK 18 ay (\% 95 GA;15,6- 20,3), metastatik hastalıkta GSK 11 ay (\% 95 GA;4,5-17,4)(p:0,003) 
Tablo 1: Hastaların demografik ve klinik özellikleri

\begin{tabular}{|l|c|}
\hline Özellikler & Sayı (\%) \\
\hline Yaş & \\
Ortanca, aralık & $59(28-76)$ \\
\hline Cinsiyet & \\
Erkek & $8(\% 38,1)$ \\
Kadın & $13(\% 61,9)$ \\
& \\
\hline Başvuru şikayeti & \\
Kanama & $10(\% 47,6)$ \\
Ağrı & $7(\% 33,3)$ \\
Kitle & $4(\% 19)$ \\
\hline Tümör lokalizasyonu & \\
Anal & $8(\% 38,1)$ \\
Rektal & $11(\% 52,4)$ \\
Anorektal & $2(\% 9,5)$ \\
\hline Tanı anında evre & \\
Evre 2 & $3(\% 15,8)$ \\
Evre 3 & $12(\% 57,9)$ \\
Evre 4 & $6(\% 26,3)$ \\
\hline Operasyon öyküsü & \\
Küratif & $15(\% 73,7)$ \\
Palyatif & $5(\% 26,3)$ \\
Yapılmadı & $1(\% 4,7)$ \\
\hline Adjuvan Interferon & \\
Var & $6(\% 28,5)$ \\
Yok & $15(\% 71,5)$ \\
\hline Tanıda metastaz durumu & \\
Var & $6(\% 28,5)$ \\
Yok & $15(\% 71,5)$ \\
\hline İpilimumab kullanımı & \\
Var & $1(\% 4,7)$ \\
Yok & $20(\% 95,3)$ \\
\hline
\end{tabular}

\section{REFERANSLAR}

1. Kothonidis K, Maassarani F, Couvreur Y, Vanhoute B, Keuleneer RD. Primary anorectal melanoma-a rare entity: case report. Journal of Surgical Case Reports.2017;3,1-3.

2. Han J, Shi C, Dong X, et al. Laparoscopic abdominoperineal resection for patients with anorectal malignant melanoma: a report of 4 cases.The Journal of Biomedical Research.2016, 30:436-40.

3. Bello DM, Smyth E, Perez D, et al. Anal versus Rectal Melanoma: Does Site of Origin Predict Outcome? Dis Colon Rectum.2013;56:150-7.

4. Feng L, Qi DJ, Zhang QF. Anorectal melanoma metastatic to the breast: a case report and review of the literature.OncoTargets and Therapy.2016:9 4969-74.

5. Gavriilidis P, Moula E, Nikolaidou A. Primary rectal malignant melanoma-Case report. HIPPOKRATIA.2013;17,4:380-1.

6. Park JH, Lee JR, Yoon HS, et al. Primary anorectal malignant melanoma treated with endoscopic mucosal resection. Intest Res.2015;13:170-4.
7. Moore WD. Recurrent melanosis of the rectum after previous removal from the verge of the anus in a managed aged 65.Lancet.1857;1:290-4.

8. Sönmez Ö, Üyetürk Ü, Helvacı K, et al. Primary anorectal malignant melanoma: rare but highly lethal malignancy. Turk J Med Sci.2012;42:1513-18.

9. Stefanou A, Nalamati SPM. Anorectal Melanoma. Clin Colon Rectal Surg.2011;24:171-6.

10. Nam S, Kim CW, Jin Baek S, et al.The clinical features and optimal treatment of anorectal malignant melanoma.Ann Surg Treat Res.2014;87:113-7.

11. Cooper PH, Mills SE, Allen MS. Malignant melanoma of the anus: report of 12 patients and analysis of 255 additional cases. Dis Colon Rectum.1982; 25:693-703.

12. Bussin D, Sterle A, Schmiegelow P, Wassenberg D, Ambe PC. Primary anorectal malignant melanoma: a rare but aggressive tumor:report of a case. World J Surg Oncol.2015;13:12.

13. Kelly P, Zagars GK, Cormier JN, Ross MI, Guadagnolo BA. Sphincter-sparing local excision and hypofractionated radiation therapy for anorectal 
melanoma:a 20-year experience. Cancer.2011;117:474755.

14. Malaguarnera G, Madeddu R, Catania VE, et al.Anorectal mucosal melanoma. Oncotarget.2018; 9:8785-800.

15. Hodi FS, O'Day SJ, McDermott DF, et al. Improved survival with ipilimumab in patients with metastatic melanoma. N Engl J Med. 2010;363:711-723.
16. Carvajal RD, Antonescu CR, Wolchok JD, Chapman $\underline{\mathrm{PB}}$, Roman RA, Teitcher J. KIT as a therapeutic target in metastatic melanoma. JAMA.2011;305:2327-34.

17. Anvari K, Izadpanahi P, Memar B. Anorectal Melanoma: a 10-year study in the North-East of Iran. Iran J Cancer Prev.2012;4:221-4.

18. Belbaraka R, Elharroudi $T$, Ismaili $N$, et al.Management of anorectal melanoma: report of 17 cases and literature review.J Gastrointest Cancer.2012;43:31-5. 